\title{
Dental attendance after treatment under dental general analgesia (DGA): a data-based follow-up study
}

\author{
M. Tilja ${ }^{1} \cdot$ P. Rajavaara ${ }^{1,2}$ (i) $\cdot$ M.-L. Laitala ${ }^{1} \cdot$ P. Pesonen ${ }^{3} \cdot$ V. Anttonen ${ }^{1,4}$
}

Received: 13 October 2017 / Accepted: 15 October 2018 / Published online: 31 October 2018

(c) The Author(s) 2018

\begin{abstract}
Aims To investigate dental attendance of patients in different age groups after dental general analgesia (DGA) and procedures performed on these patients during the DGA and in dental care after the DGA during the follow-up period of almost 3 years. Methods The study population consisted of 66 patients who were treated under DGA at a municipal health centre in Oulu, Finland between September 2010 and June 2011. The electronic patient files of the DGA patients were accessible for data collection for the follow-up period of nearly 3 years. The statistical analyses included Chi square tests and logistic regression modelling.

Results Approximately every sixth (14.9\%) dental visit was missed or cancelled and nearly half (43.9\%) of the studied subjects had at least one missed or cancelled appointment. The factors increasing the risk of missed or cancelled appointments and dental avoidance were endodontic treatment (OR 3.62), need of more than five dental restorations (OR 3.47), tooth extractions due to caries (OR 2.22), and male gender (OR 1.80). A total of $45.5 \%$ of the patients received non-invasive procedures. Conclusions Patients who need DGA are evidently risk patients considering dental attendance. Nearly half of the patients in this study had non-attended or cancelled appointments. DGA patients' need of treatment after DGA is extensive, even comparable to the amount of procedures generally performed under DGA. The quality or amount of preventive procedures do not appear to be at the required level to reduce the number of non-attended appointments.
\end{abstract}

Keywords Dental general analgesia $\cdot$ Dental attendance $\cdot$ Dental avoidance $\cdot$ Need for treatment

\section{Introduction}

Dental caries is the most common reason for treatment under (DGA) (Jordan et al. 2016). It is commonly associated with dental fear or poor cooperation (Vinckier et al. 2001; Savanheimo et al. 2012; Jankauskiene et al. 2013; Tanner et al. 2013; Taskinen et al. 2014). Dental fear and anxiety have diminished in the past decades, most prominently among

P. Rajavaara

paivi.rajavaara@gmail.com

1 Research Unit of Oral Health Sciences, Department of Cariology, Endodontology and Pediatric Dentistry, University of Oulu, Oulu, Finland

2 Dental Teaching Unit and Unit of Specialized Care, Municipal Health Centre, Oral Health Care, Oulu, Finland

3 Research Unit of Oral Health Sciences, University of Oulu, Oulu, Finland

4 Medical Research Center, Oulu University Hospital, University of Oulu, Oulu, Finland women in the industrialised countries (Astrøm et al. 2011), but dental fear is still slightly more common among women than men (Milgrom et al. 2010; Humphris and King 2011; Taskinen et al. 2014). Although women are reported having more dental fear, they have more dental visits compared to men. However, men have more need for treatment.

While dental caries is strongly associated with dental fear and DGA, it is not the only explanation for fear or DGA. Dental caries has a polarised nature, which means that a small proportion of the population has most of the carious teeth. The occurrence of this polarisation is most notable in males (Tanner et al. 2013; Grund et al. 2015). Tanner et al. (2013) observed that approximately $30 \%$ of their study population had nearly all (90\%) of the carious teeth and approximately $10 \%$ had half of the carious teeth. The study of Grund et al. (2015) reported consistent results: approximately 35\% of the population had $90 \%$ of the carious teeth and $15 \%$ had half of the carious teeth.

Previous negative experiences in dental care are commonly important contributors to the development of dental 
fear (Skaret et al. 1999; Milgrom et al. 2010). The causes of negative experiences have been reported to be pain, drilling and local analgesia (Rantavuori et al. 2004; Humphris and King 2011) together with a sense of helplessness during dental care (Oosterink et al. 2009; Humphris and King 2011). Interestingly, unfinished dental treatments before the age of 18 years (Skaret et al. 1999), as well as irregular dental attendance at an older age (Pohjola et al. 2007), have been shown to predict dental fear. Although DGA should be considered as the last alternative in dental care, it has become a daily practice; as many as $0.2 \%$ of children are treated under DGA (Savanheimo et al. 2012). The reasons for this may include the development of sedative substances and methods, increase of parental knowledge of the option of DGA, as well as professional skills of the practitioners (Vinckier et al. 2001; Nelson and Xu 2015).

While DGA has become a common dental practice, studies investigating dental attendance and dental procedures after DGA are scarce. Most of the studies on the topic evaluate the change in the oral health related quality of life (OHRQoL) after DGA. The OHRQoL can be determined, for example, on the basis of a questionnaire completed by the parents, and according to the literature, DGA improves the quality of life. Studies show that the OHRQoL improved at the 1, 3 or 12 month's follow-up after the DGA compared to the OHRQoL before the DGA (Jankauskiene et al. 2014; El-Meligy et al. 2016; Yawary et al. 2016). Patients' physical and psychological wellbeing was reported to have increased significantly, and domesticity also improved due to the decrease in the distress of the caregivers (Jankauskiene et al. 2014; Ridell et al. 2015; Yawary et al. 2016).

The aims of this data-based study were to investigate dental attendance of patients after the DGA treatment during a follow-up period of nearly 3 years in different age groups, as well as the dental procedures performed during and after the DGA. We hypothesised that patients treated under DGA are commonly missing or cancelling appointments after their DGA. Because dental caries is such a common cause of DGA, it is probable that these patients still need invasive treatments and sedation even after the DGA. It was also hypothesised that the proportion of acute care visits is high and the number of prophylactic visits low.

\section{Materials and methods}

\section{Subjects and data collection}

This retrospective study was based on patient documents. The files of all the patients $(n=66)$ who had received treatment under DGA at a municipal health centre in the city of Oulu, Finland during the period from September 2010 to June 2011 were examined. All the patients had been evaluated to be in need of DGA and be physically healthy (max value 2 according to the ASA criteria - the American Society of Anaesthesiologists).

The collection of data from the electronic patient files of the City of Oulu covered the period from the first DGA up to 36 months thereafter. The documents and treatment periods were from the period of September 2010-June 2013. The patients' age (years), gender, first analgesic treatment (date), diagnoses registered after the DGA (ICD-10), and number of procedures under the DGA (prevention, filling, endodontic treatment, extraction) were collected from the electronic patient documents by their procedure codes. In addition, the number of treatment visits after the DGA, number of missed appointments with or without cancelling, procedures (prevention, filling, endodontic treatment, extraction), and number of visits where sedation $\left(\mathrm{N}_{2} \mathrm{O}_{2}\right.$, premedication) or cognitive therapy (CBT) was used after the first DGA (one procedure code for inhalation sedation and one for premedication/CBT) were also collected. All the data were collected manually from the electronic documents by one author (MT).

\section{Statistics}

The data analyses and graphs were performed with the IBM SPSS Statistics 21 (IBM, US) using crosstabs and frequencies. The association between the missed or cancelled appointments and the total number of appointments was determined by using the Pearson Chi square test and Fisher's exact tests. Statistical significance was determined by the $p$ values below 0.05 .

The adjusted odds ratios (OR) and their 95\% CI were calculated using two logistic regression models, where the dependent variable was the number of missed/cancelled appointments. The best independent variables were included in the models. The independent variables used in the first model were gender, restorations and extractions and in the second model gender, restorations and endodontic treatment.

\section{Ethical considerations}

The Ethical Board of the Northern Ostrobothnia Hospital District, Finland granted its permission for the study (EETTMK: 62/2012; § 232). Informed consent was obtained from all individual participants included in this study. A written consent for participation was collected from all the subjects aged 12 years or older. The parents gave their written consent for participation for the subjects under the age of 14 years. The data were analysed anonymously. 


\section{Results}

The study population comprised 66 patients and was slightly dominated by women $(56.1 \%, \mathrm{n}=37)$. The mean age of the participants was 15.7 years (SD 12.8; median 11.0, min 3 , max 68 ). In total, the patients had 328 visits during the follow-up period. Among the study group, three individuals had only records of the DGA in their patient files without any notices of any follow-up visits.

On average, the participants had 4.7 (SD 3.39; median 4.00, min 1, max 18) dental treatment visits after the DGA (including the DGA). A quarter of the study group had seven visits or more. The proportion of those with at least four visits was slightly higher among males (58.6\%) than females (54.0\%) (Table 1).

\section{Dental procedures under DGA}

The most common procedures under DGA were dental restorations; 55 patients $(83.3 \%)$ had on average 4.6 restorations ( $\min 0, \max 19)$. The second most common procedure was tooth extractions. Fifty-two patients had on average 2.6 extractions ( $\min 0 ; \max 14)$ under DGA-only in 11

Table 1 Number of appointments after dental general analgesia (DGA) according to gender

\begin{tabular}{llllll}
\hline Gender & \multicolumn{5}{l}{ Number of appointments after DGA, n (\%) } \\
\cline { 2 - 6 } & None & $1-3$ & \multicolumn{1}{c}{$4-6$} & $\geq 7$ & Total, n (\%) \\
\hline Female & $2(5.4)$ & $15(40.5)$ & $11(29.7)$ & $9(24.3)$ & $37(56.1)$ \\
Male & $1(3.4)$ & $11(37.9)$ & $9(31.0)$ & $8(27.6)$ & $29(43.9)$ \\
Total, n (\%) & $3(4.5)$ & $26(39.4)$ & $20(30.3)$ & $17(25.8)$ & $66(100)$ \\
\hline
\end{tabular}

extraction cases the cause was other than dental caries (e.g. orthodontic treatment or impacted tooth). Sixty-one preventive (non-invasive) procedures were performed on 30 patients, and 34 of those procedures concerned fissure sealing. Eighteen patients had a total of 23 root canal treatments, of which 9 were done on incisors, canines or premolars, 4 on molars and 10 on primary teeth. There were 12 completed root canal fillings on altogether 9 patients. Only one of the patients received more than one root filling; he had four root fillings, all in teeth with one canal (Table 2).

\section{Dental procedures after DGA}

Twenty-five (37.9\%) patients needed dental emergency care during the follow-up period, and they had a total of 38 emergency visits. Only in three cases, the cause of the visit was dental trauma. Almost half (43.9\%) of the study subjects had cancelled or missed appointments, the total proportion being $14.9 \%$ of all the scheduled appointments $(n=328)$. Only six patients cancelled their appointments $(n=11)$, but three of those patients had also missed appointments. Cancelling an appointment was equally spread throughout the follow-up period, but missed appointments were clearly most common right after the DGA. During the first three appointments after the DGA, the proportion of missed appointments was $13.9 \%$, whereas the same proportion for the later appointments was 9.1\% ( $\mathrm{p}=0.011)$ (Table 3). There were 26 patients who had non-attended appointments.

After the DGA, only about $15 \%$ of the subjects needed extractions and less than $10 \%$ endodontic treatment; however, almost half needed restorative treatment. The maximum number of restorative procedures for one patient was 28. After the DGA, there were 21 tooth extractions done on

Table 2 Distribution of individuals according to the number of different procedures under and after dental general analgesia (DGA)

\begin{tabular}{|c|c|c|c|c|}
\hline \multirow[t]{2}{*}{ Procedure type } & \multicolumn{4}{|c|}{ Frequency of procedures under DGA, $n(\%)$} \\
\hline & None & $1-3$ & $\geq 4$ & Total \\
\hline Restoration & $11(16.7)$ & $15(22.7)$ & $40(60.6)$ & 66 \\
\hline Extraction & $14(21.2)$ & $32(48.5)$ & $20(30.3)$ & 66 \\
\hline Root canal treatment & $48(72.7)$ & $17(25.8)$ & $1(1.5)$ & 66 \\
\hline Root filling & $57(86.4)$ & $8(12.1)$ & $1(1.5)$ & 66 \\
\hline \multirow[t]{3}{*}{ Non-invasive care } & $36(54.5)$ & $25(37.9)$ & $5(7.6)$ & 66 \\
\hline & \multicolumn{4}{|c|}{ Frequency of procedures after DGA, n (\%) } \\
\hline & None & $1-3$ & $\geq 4$ & Total $^{\mathrm{a}}$ \\
\hline Restoration & $35(55.5)$ & $17(27.0)$ & $11(17.5)$ & 63 \\
\hline Extraction & $53(84.1)$ & $8(12.7)$ & $2(3.2)$ & 63 \\
\hline Root canal treatment & $58(92.1)$ & $5(7.9)$ & $0(0.0)$ & 63 \\
\hline Root filling & $57(90.5)$ & $5(7.9)$ & $1(1.6)$ & 63 \\
\hline Non-invasive care & $30(47.6)$ & $23(36.5)$ & $10(15.9)$ & 63 \\
\hline
\end{tabular}

${ }^{\mathrm{a}}$ Three patients had no visits after DGA 
Table 3 Distribution of missed and cancelled appointments after dental general analgesia (DGA) according to gender in different age groups

\begin{tabular}{lcccrr}
\hline \multicolumn{1}{l}{ Appointments, $\mathrm{n}(\%)$} & & & \\
\hline Age (years) & Missed & Cancelled & Missed +cancelled & Attended & \multicolumn{1}{c}{ Total } \\
\hline Male & & & & & \\
$\leq 15$ & 13 & 3 & $16(13.4)$ & $103(86.6)$ & $119(77.3)$ \\
$>15$ & 7 & 1 & $8(22.9)$ & $27(77.1)$ & $35(22.7)$ \\
Total & 20 & 4 & $24(15.6)$ & $130(84.4)$ & $154(47.0)$ \\
Female & & & & & \\
$\leq 15$ & 7 & 2 & $9(8.5)$ & $97(91.5)$ & $106(60.9)$ \\
$>15$ & 11 & 5 & $16(23.5)$ & $52(76.5)$ & $68(39.1)$ \\
Total & 18 & 7 & $25(14.4)$ & $149(85.6)$ & $174(53.0)$ \\
& 38 & 11 & $49(15.0)$ & $279(85.0)$ & $328(100)$ \\
\hline
\end{tabular}

10 patients. The maximum number of extractions during one visit after the DGA was five. Endodontic treatment was carried out on five patients, who had 11 procedures in total. Non-invasive care after the DGA was given to $33(52.4 \%)$ patients during 72 (22.0\%) dental visits (Table 2; Fig. 1).
During their dental visits after the DGA, eight patients received inhalation sedation $\left(\mathrm{N}_{2} \mathrm{O}_{2}\right)$, five of whom only once, one twice and two three times. Twenty-three patients out of 63 were given premedication, and almost all the patients had cognitive behavioural treatment $(\mathrm{CBT})$ with or without

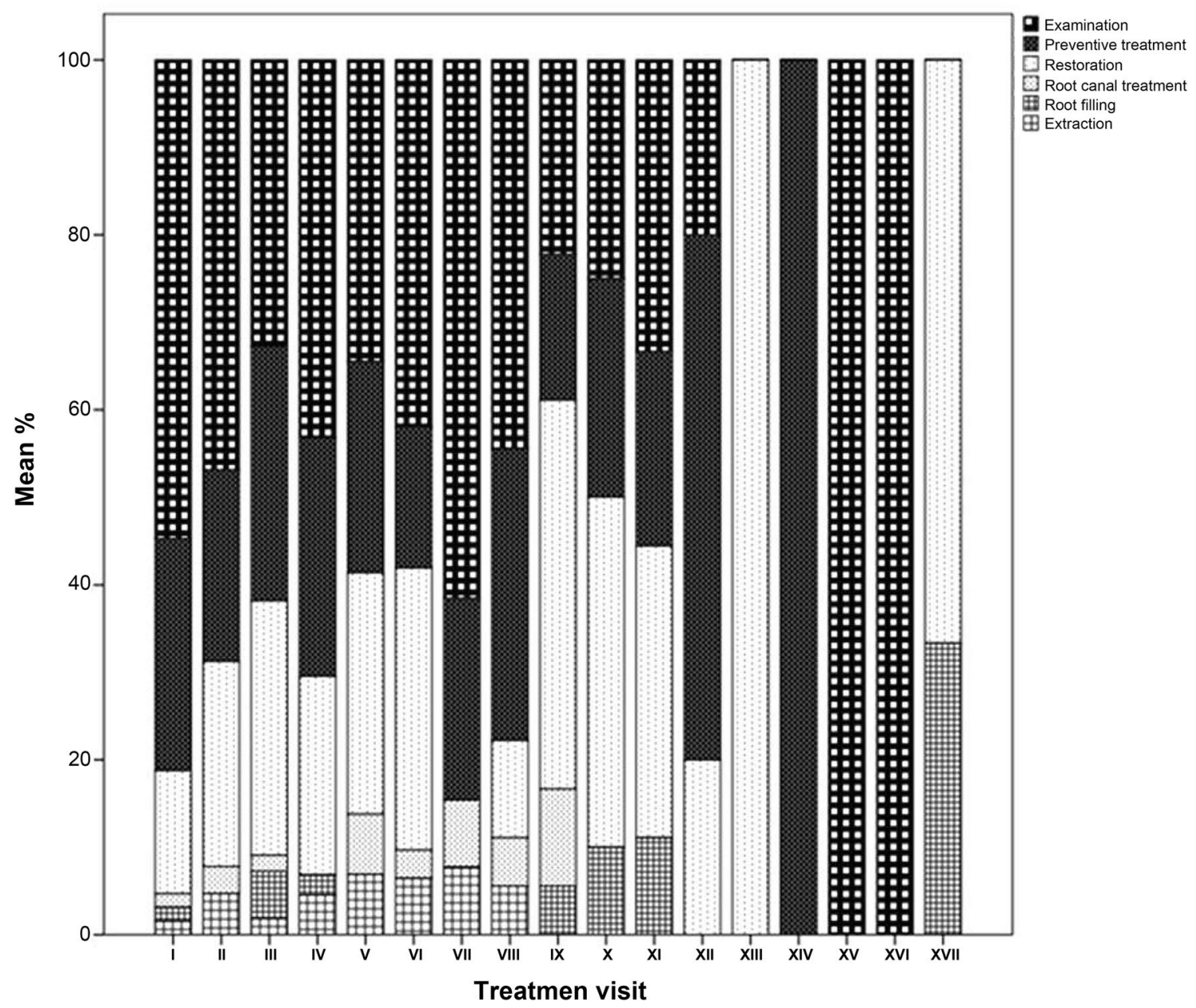

Fig. 1 Distribution of procedures performed during different treatment visits 
sedation. Local analgesia was used on 53 patients during 109 (27.7\%) treatment visits.

After the DGA, missed or cancelled appointments associated with male gender (OR 1.8; 95\% CI 0.61-5.13) and extractions due to caries (OR 2.22; 95\% CI 0.54-9.10). The only association that was statistically significant was "need of more than five dental restorations' (OR 3.47; 95\% CI 1.14-10.54). When root canal treatments were also included in the logistic modelling, the risk of missed or cancelled appointments increased (OR 3.62; 95\% CI 1.00-13.04).

\section{Discussion}

The strength of this present study was that here was access to the patient documents, which included data about the performed procedures and missed or cancelled appointments. This enabled to search for a possible association between non-attendance and need of treatment from each patient's dental treatment history. Another advantage was that the same population had been studied earlier with respect to patients' self-reported indication for DGA (Taskinen et al. 2014).

Most studies concerning dental attendance or dental avoidance in relation to DGA patients focus on investigating whether the patients are registered to have dental fear or dental anxiety (Wogelius and Poulsen 2005; Milgrom et al. 2010; Savanheimo et al. 2012). Studies investigating dental attendance after the DGA are scarce. Savanheimo and Vehkalahti (2014) have reported that after DGA, 26\% of the patients missed the control visit and in total two out of three had one or more missed appointments during the 4 years' follow-up period. In the present study it was observed that after the DGA, a need of more than five dental restorations, male gender, tooth extractions due to caries, and root canal treatments increased the risk of missed or cancelled appointments. This was in line with the findings of Skaret et al. (1999) that dental caries, among other factors, often indicates patients being prone to missing appointments and needing DGA treatments. Extensive need of treatment may, indeed, nowadays easily lead to recurrent DGA treatments, especially for patients with dental fear or poor cooperation.

The present study findings are in line with an earlier study, which reported that $38 \%$ of children with dental anxiety but had not been treated under DGA, had missed appointments (Wogelius and Poulsen 2005). Here, missed or cancelled appointments indicate dental fear, which was reported to be present in this study population by Taskinen et al. (2014). The fact that the first three appointments right after the DGA were commonly missed, indicated that after the DGA patients were free of pain. It is obvious that dental fear should be treated to reduce the need for DGA treatments and, thus to reduce the amount of missed and cancelled appointments.

Dental procedures performed under the DGA and during the follow-up dental visits were similar. The present study results are in concordance with a Finnish study, which reported a variety of treatments given to patients under DGA; the non-invasive treatments were more common in the present study than in the study by Savanheimo et al. (2012). Findings of Vinckier et al. (2001) are also in line with the present study. Both studies support the idea that there is always a group of people within populations with a high risk of dental caries. All efforts should be put on motivating these people to improve their self-care and on utilising all necessary prophylactic means. It seems that the quality or amount of preventive procedures are not at the required level to reduce the number of non-attended appointments.

Although the data consisted of the complete patient documents of all the subjects from their first DGA treatment throughout the follow-up period of up to 3 years, the study has its limitations. The patients were treated by different dentists, and completing the patient documents may not have been fully standardised. Data concerning the patients' previous dental attendance were not accessible. Some of the patients may also have visited other dental practices after being treated under DGA at the municipal health centre in Oulu, which information and possible data on such dental attendance were not available. Furthermore, the total number of the study subjects was fairly limited, and the size of the subgroups by gender and age remained small.

\section{Conclusions}

Patients who are treated under (DGA) seem to be prone to non-attending or cancelling dental appointments. After DGA, the need for dental treatment commonly remains extensive, and the number of procedures performed during DGA is comparable to the amount of procedures performed after (DGA). To avoid further DGAs, organised prophylaxis after DGA should be conducted.

Acknowledgements Open access funding provided by University of Oulu including Oulu University Hospital.

\section{Compliance with ethical standards}

Conflict of interest The authors declare that they have no conflict of interest.

Open Access This article is distributed under the terms of the Creative Commons Attribution 4.0 International License (http://creativeco mmons.org/licenses/by/4.0/), which permits unrestricted use, distribution, and reproduction in any medium, provided you give appropriate 
credit to the original author(s) and the source, provide a link to the Creative Commons license, and indicate if changes were made.

\section{References}

Astrøm AN, Skaret E, Haugejorden O. Dental anxiety and dental attendance among 25-year-olds in Norway: time trends from 1997 to 2007. BMC Oral Health. 2011;11:10.

El-Meligy O, Maashi M, Al-Mushayt A, Al-Nowaiser A, Al-Mubark $\mathrm{S}$. The effect of full-mouth rehabilitation on oral health-related quality of life for children with special health care needs. J Clin Pediatr Dent. 2016;40:53-61.

Grund K, Goddon I, Schuler IM, Lehmann T, Heinrich-Weltzien R. Clinical consequences of untreated dental caries in German 5- and 8-year-olds. BMC Oral Health. 2015;15:140.

Humphris G, King K. The prevalence of dental anxiety across previous distressing experiences. J Anxiety Disord. 2011;25:232-6.

Jankauskiene B, Virtanen JI, Kubilius R, Narbutaite J. Treatment under dental general anesthesia among children younger than 6 years in Lithuania. Medicina (Kaunas). 2013;49:403-8.

Jankauskiene B, Virtanen JI, Kubilius R, Narbutaite J. Oral healthrelated quality of life after dental general anaesthesia treatment among children: a follow-up study. BMC Oral Health. 2014;14:81.

Jordan AR, Becker N, Johren HP, Zimmer S. Early childhood caries and caries experience in permanent dentition: a 15-year cohort study. Swiss Dent J. 2016;126:114-25.

Milgrom P, Newton JT, Boyle C, Heaton LJ, Donaldson N. The effects of dental anxiety and irregular attendance on referral for dental treatment under sedation within the National Health Service in London. Community Dent Oral Epidemiol. 2010;38:453-9.

Nelson TM, Xu Z. Pediatric dental sedation: challenges and opportunities. Clin Cosmet Investig Dent. 2015;7:97-106.

Oosterink FM, de Jongh A, Aartman IH. Negative events and their potential risk of precipitating pathological forms of dental anxiety. J Anxiety Disord. 2009;23:451-7.
Pohjola V, Lahti S, Vehkalahti MM, Tolvanen M, Hausen H. Association between dental fear and dental attendance among adults in Finland. Acta Odontol Scand. 2007;65:224-30.

Rantavuori K, Lahti S, Hausen H, Seppa L, Karkkainen S. Dental fear and oral health and family characteristics of Finnish children. Acta Odontol Scand. 2004;62:207-13.

Ridell K, Borgstrom M, Lager E, et al. Oral health-related quality-oflife in Swedish children before and after dental treatment under general anesthesia. Acta Odontol Scand. 2015;73:1-7.

Savanheimo N, Vehkalahti MM. Five-year follow-up of children receiving comprehensive dental care under general anesthesia. BMC Oral Health. 2014;14:154.

Savanheimo N, Sundberg SA, Virtanen JI, Vehkalahti MM. Dental care and treatments provided under general anaesthesia in the Helsinki Public Dental Service. BMC Oral Health. 2012;12:45.

Skaret E, Raadal M, Berg E, Kvale G. Dental anxiety and dental avoidance among 12 to 18 year olds in Norway. Eur J Oral Sci. 1999; 107:422-8.

Tanner T, Kamppi A, Pakkila J, et al. Prevalence and polarization of dental caries among young, healthy adults: cross-sectional epidemiological study. Acta Odontol Scand. 2013;71:1436-42.

Taskinen H, Kankaala T, Rajavaara P, et al. Self-reported causes for referral to dental treatment under general anaesthesia (DGA): a cross-sectional survey. Eur Arch Paediatr Dent. 2014;15:105-12.

Vinckier F, Gizani S, Declerck D. Comprehensive dental care for children with rampant caries under general anaesthesia. Int J Paediatr Dent. 2001;11:25-32.

Wogelius P, Poulsen S. Associations between dental anxiety, dental treatment due to toothache, and missed dental appointments among six to eight-year-old Danish children: a cross-sectional study. Acta Odontol Scand. 2005;63:179-82.

Yawary R, Anthonappa RP, Ekambaram M, McGrath C, King NM. Changes in the oral health-related quality of life in children following comprehensive oral rehabilitation under general anaesthesia. Int J Paediatr Dent. 2016;26:322-9. 